\title{
Physical Experiments of Tectonic Deformation and Processes: Building a Strong Community
}

Michele L. Cooke, University of Massachusetts-Amherst, Amherst, Massachusetts 01003-9297, USA; Jacqueline E. Reber, lowa State University, Ames, lowa 50011-3212, USA; Saad Haq, Purdue University, West Lafayette, Indiana, 47907, USA

\section{ABSTRACT}

The recent revolution in the analysis of physical experiments of tectonic processes has provided new quantitative tools to analyze their outcomes. Physical experiments using scaled analog models are unique in providing information on complex three-dimensional deformation where processes can be directly observed. These observations critically complement insights gained from field and analytical/numerical investigations. Recent innovations in rheologic testing, digital image processing, and data collection are revolutionizing how we use experiments to provide insight into crustal deformation. At the same time, we are seeing the benefits of physical experiments in classroom teaching by engaging students in hypothesis testing and hands-on laboratory experience.

Strengthening of the community of physical experimentalists and instructors using analog materials to simulate tectonic processes will enhance our understanding of these processes, lend more power both to interpretations of field observations and to validation of numerical models, and deepen student understanding of tectonic mechanisms. A step toward a stronger community has been made with a recent workshop on physical modeling of tectonic processes, and this report is one outcome of that workshop.

\section{THE REVOLUTION IN PHYSICAL EXPERIMENTS}

Two hundred years ago, Hall (1815) published the first research paper to use physical experiments using analog materials to investigate mountain belt formation. Since these very first experiments, physical models in earth science have not only been useful tools for visualizing deformation but also have great power to investigate physical processes that govern deformation. For example, the innovative experiments of Tapponnier et al. (1982) and Davis et al. (1983), each with over 2,000 citations, have transformed our thinking about tectonic processes. Carefully scaled analog models provide a means to directly observe deformational processes that within Earth's crust are too slow and too large to directly document (Hubbert, 1937). Furthermore, within such experiments we have control over boundary conditions and material properties so that we can directly assess their effect on deformation. While fieldwork and analytical and numerical models are essential tools for investigating crustal processes, they often do not inform all aspects of the deformational story. Using physical experiments in conjunction with field observations and analytical/numerical investigations provides a strong three-legged stool upon which we can build a robust understanding of crustal deformation processes (Fig. 1).

Advances in experimental procedures have been developed at physical modeling laboratories within both academia and the petroleum industry. The past 10 years have seen a revolution within physical modeling of crustal deformation spurred by the utilization of new innovative analog materials (e.g., Di Giuseppe et al., 2015), systematic rheologic testing (e.g., Klinkmüller et al., 2016), incorporation of laser and image processing techniques for data analysis (e.g., Haq, 2012), measuring in situ stress (e.g., Herbert et al., 2015), and reconstruction of the evolution of complex 3D structures (e.g., Colletta et al., 1991). These advances all strengthen the quantitative rigor of physical modeling of tectonic processes. The vanguard of this recent revolution has been in Europe, which has many active laboratories staffed with technicians implementing and advancing these new technologies. While presently a typical experimental laboratory in the United States is run by a single principal investigator with his or her students, European labs are run with a team of lead scientists with tens of students. Consequently, the core of the experimental community is in Europe, where experimentalists host regular workshops and conference sessions focused on physical modeling. Strengthening the U.S.

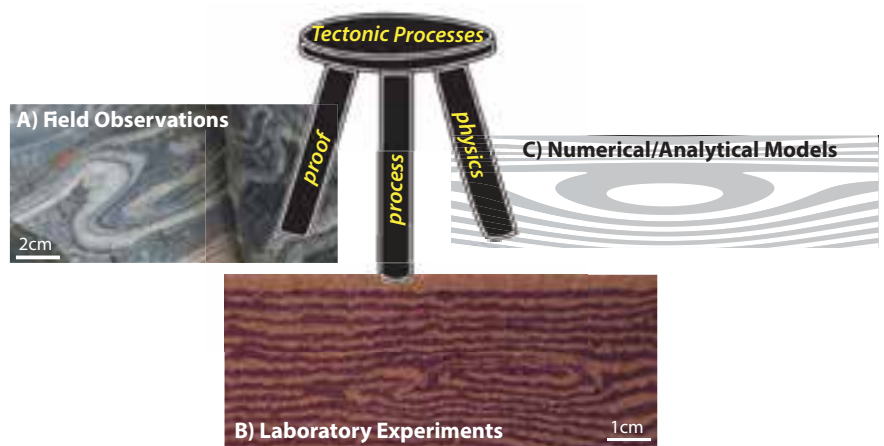

Figure 1. Deep understanding of crustal deformation relies on three approaches: field measurements of deformation, physics-based predictions of deformation, and direct documentation of deformational processes within laboratory experiments. To illustrate the power of the tectonics three-legged stool, we show results from a fully integrated study on the development of sheath folds in simple shear. (A) Sheath fold from Cap de Creus, Spain. (B) Photo from a physical experiment investigating the impact of layer viscosity contrast on the fold formation (Reber et al., 2013). (C) Cross section from an analytical model investigating the effect of total shear strain (Reber et al., 2012). 
experimental community requires coordinated and structured growth in the numbers of researchers involved in physical experiments as well as instructors engaging students with classroom experiments.

\section{PHYSICAL EXPERIMENTS PROVIDE CRITICAL INSIGHTS}

A strong U.S. physical modeling community will have manifold benefits for research and teaching in tectonics. Below are a few examples of the insights provided by experimental data that cannot be gained by other approaches.

\section{Provide Data for Calibration of Numerical Models}

Numerical simulations of crustal deformation are plagued with uncertainties about crustal structure, strength, and evolution. Within physical experiments, the boundary conditions are known, the material rheology is constrained, and the evolution of deformation can be directly observed. Experimental results are the perfect data sets for validating our numerical models before we apply them to crustal systems.

\section{Provide Insight into Specific Processes}

Within the laboratory, we can isolate single mechanisms contributing to tectonic deformation. Scaled physical experiments with controlled boundary conditions and constrained material rheology allow us to pinpoint the impact of targeted processes. Insights from this approach can assist the interpretation of field data where multiple processes and mechanisms may have acted to produce complex deformation patterns.

\section{Outreach and Teaching}

Understanding geologic time is one of the hardest concepts for students new to geology. Physical experiments can assist these students because they demonstrate slow geologic processes happening over millions of years within minutes on the tabletop. This helps students to integrate both space and time as they directly observe the three-dimensional deformation and temporal evolution of structures. The hands-on approach complements other styles of teaching within the classroom and reaches student with diverse learning strengths. Additionally, physical experiments provide an accessible means for hypothesis testing in the classroom because the boundary conditions and material properties can be manipulated (Feldman et al., 2010). Furthermore, the visual and hands-on nature of physical experiments engages and inspires students and the public alike.

Physical experiments provide the only mechanism for direct observation of the processes of tectonic deformation. Consequently, they hold the key to understanding information obtained in the field that documents the results of deformation and analytical/ numerical models that capture the physics of deformation. To best understand tectonic deformation, we need to use a variety of approaches, including physical experimentation.

\section{FUTURE DIRECTIONS}

In an effort to strengthen and expand the U.S. community of physical experimentalists in tectonics, the U.S. National Science Foundation sponsored a workshop in 2015 on "Analog Modeling of Tectonic Processes" at the University of Massachusetts-Amherst with 46 participants. This workshop was a great success and helped connect researchers and teachers using physical modeling.
One of the outcomes of the workshop was learning that it is essential to continue growing the U.S. community of experimentalists, to increase networking among the researchers so that we can advance our techniques, enable sharing of techniques and teaching approaches involving physical models, and to facilitate collaboration between experimentalists and others investigating tectonic processes. A valuable aspect of the 2015 workshop was the presentation of innovative curricula, which inspired participants to implement new activities within their courses. Having experiment-focused workshops on a regular basis as well as continued support for research and teaching involving physical modeling will grow this community and strengthen our understanding of deformational processes. A successor workshop planned for 2017 will continue this effort.

Within the next ten years we hope to continue strengthening the collaboration between field geologists, numerical modelers, and experimentalists to build a stronger three-legged stool upon which we can advance our tectonic understanding.

\section{REFERENCES CITED}

Colletta, B., Letouzey, J., Pinedo, R., Ballard, J.F., and Balé, P., 1991, Computerized $\mathrm{X}$-ray tomography analysis of sandbox models: Examples of thin-skinned thrust systems: Geology, v. 19, no. 11, p. 1063-1067.

Davis, D., Suppe, J., and Dahlen, F.A., 1983, Mechanics of fold-and-thrust belts and accretionary wedges: Journal of Geophysical Research, Solid Earth, v. 88, B2, p. 1153-1172.

Di Giuseppe, E., Corbi, F., Funiciello, F., Massmeyer, A., Santimano, T.N., Rosenau, M., and Davaille, A., 2015, Characterization of Carbopol ${ }^{\circledR}$ hydrogel rheology for experimental tectonics and geodynamics: Tectonophysics, v. 642, p. 29-45, doi: 10.1016/j.tecto.2014.12.005.

Feldman, A., Cooke, M.L., and Ellsworth, M., 2010, The Classroom Sandbox: A physical model for scientific inquiry: Science Teacher (Normal, Ill.), Dec., p. 58-62.

Hall, J., 1815, On the vertical position and convolutions of certain strata and their relation with granite: Transactions of the Royal Society of Edinburgh, v. 7, p. 79-108, doi: 10.1017/S0080456800019268.

Haq, S.S., 2012, Out-of-sequence thrusting in experimental Coulomb wedges: Implications for the structural development of mega-splay faults and forearc basins: Geophysical Research Letters, v. 39, no. 20, doi: 10.1029/ 2012GL053176.

Herbert, J.W., Cooke, M.L., Souloumiac, P., Madden, E.H., Mary, B.C., and Maillot, B., 2015, The work of fault growth in laboratory sandbox experiments: Earth and Planetary Science Letters, v. 432, p. 95-102, doi: 10.1016/j.epsl.2015.09.046.

Hubbert, M.K., 1937, Theory of scale models as applied to the study of geologic structures: GSA Bulletin, v. 48, no. 10, p. 1459-1520, doi: 10.1130/ GSAB-48-1459.

Klinkmüller, M., Schreurs, G., Rosenau, M., and Kemnitz, H., 2016, Properties of granular analogue model materials: A community wide survey: Tectonophysics, v. 684, p. 23-38, doi: 10.1016/j.tecto.2016.01.017.

Reber, J.E., Dabrowski, M., and Schmid, D.W., 2012, Sheath fold formation around slip surfaces: Terra Nova, v. 24, p. 417-421, doi: 10.1111/j.1365-3121 .2012.01081.x.

Reber, J.E., Galland, O., Cobbold, P.R., and Le Carlier de Veslud, C., 2013, Experimental study of sheath fold development around a weak inclusion in a mechanically layered matrix: Tectonophysics, v. 586, p. 130-144, doi: 10.1016/j.tecto.2012.11.013.

Tapponnier, P., Peltzer, G., Le Dain, A.Y., Armijo, R., and Cobbold, P., 1982, Propagating extrusion tectonics in Asia: New insights from simple experiments with plasticine: Geology, v. 10, no. 12, p. 611-616, doi: 10.1130/0091-7613(1982)10<611:PETIAN>2.0.CO;2.

Manuscript ReCeived 27 May 2016

Revised MANUSCRIPT RECEIVED 26 Aug. 2016

Manuscript accepted 10 Sept. 2016 